\title{
Travestis e organizações: o papel da comunicação na construção de espaços organizacionais
}

\author{
Transvestites and organizations: the role of communication in the \\ construction of organizational spaces
}

\section{Travestis y organizaciones: el papel de la comunicación en la construcción de espacios organizacionales}

Guilherme Lopes Teixeira ${ }^{1, a}$

teixeira.guilherme1996@gmail.com | https://orcid.org/o0oo-0001-6328-4491

Maria Eugênia Porém ${ }^{1, b}$

maria.porem@unesp.br | https://orcid.org/o0o0-0002-0761-7797

${ }^{1}$ Universidade Estadual Paulista Júlio de Mesquita Filho. São Paulo, SP, Brasil.

a Graduação em Comunicação Social (Relações Públicas) pela Universidade Estadual Paulista Júlio de Mesquita Filho.

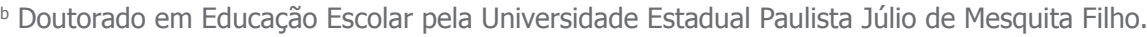

\section{Resumo}

Este artigo tem como objetivo provocar reflexões sobre o papel da comunicação na inclusão de travestis no ambiente organizacional. Parte-se do pressuposto de que as organizações são um espaço marcado pela discriminação e preconceito contra outras identidades que não sejam a do homem, branco, cisgênero e heterossexual. Utilizou-se pesquisa conceitual, de caráter bibliográfico e interpretativo, norteada por estudos de comunicação e de gênero. Considerando a visão da comunicação como fator de humanização, este ensaio resulta em uma reflexão acerca do potencial transformador da comunicação e da necessidade do comunicador atual promover espaços de diálogo e inclusão nas organizações. Como conclusão, optou-se por apresentar um esboço de diretrizes para a criação de um ambiente preparado para receber a travesti, para valorizá-la e reconhecê-la como indivíduo e também como parte de um todo.

Palavras-chave: Gênero; Travestis; Inserção profissional; Organizações; Comunicação; Inclusão. 


\begin{abstract}
This article aims to promote reflections on the role of communication in the inclusion of transvestites in the organizational environment. It is assumed that organizations are a space marked by discrimination and prejudice against identities other than the man, white, cisgender and heterosexual. A conceptual research was used, with bibliographical and interpretative character, based on studies of communication and gender. If we consider the communication as a humanization factor, this essay results in a reflection on the transforming potential of communication and on the need of the current communicator to promote spaces to dialogue and inclusion in organizations. As a conclusion, it was decided to present an outline of guidelines for the development of an environment prepared to receive the transvestite, to value her and to recognize her as an individual and also as part of the whole.
\end{abstract}

Keywords: Gender; Transvestites; Professional insertion; Organizations; Communication; Inclusion.

\title{
Resumen
}

Este artículo tiene como objetivo provocar reflexiones sobre el papel de la comunicación en la inclusión de travestis en el ambiente organizacional. Se parte del supuesto de que las organizaciones son um espacio marcado por la discriminación y por el prejuicio contra identidades distintas del hombre, blanco, cisgénero y heterosexual. Se utilizó de una investigación conceptual, de carácter bibliográfico e interpretativo, orientada por estudios de comunicación y de género. Considerando la visión de la comunicación como factor de humanización, este ensayo resulta en una reflexión acerca del potencial transformador de la comunicación y de la necesidad del comunicador contemporáneo promover espacios de diálogo e inclusión en las organizaciones. Como conclusión, se optó por presentar un esbozo de directrices para la creación de un ambiente preparado para recibir la travesti, para valorarla y reconocerla como individuo y también como parte del todo.

Palabras clave: Género; Travestis; Inserción profesional; Organizaciones; Comunicación; Inclusión.

Este texto compõe o dossiê $\mathbf{4 0}$ anos do movimento LGBT no Brasil: comunicação, saúde e direitos humanos.

Contribuição dos autores:

Concepção e desenho do estudo: Guilherme Lopes Teixeira.

Aquisição, análise ou interpretação dos dados: Guilherme Lopes Teixeira.

Redação do manuscrito: Guilherme Lopes Teixeira.

Revisão crítica do conteúdo intelectual: Maria Eugênia Porém.

Declaração de conflito de interesses: não há.

Fontes de financiamento: não houve.

Considerações éticas: não há.

Agradecimentos/Contribuições adicionais: não há.

Histórico do artigo: submetido: 31 jan. 2018 | aceito: 22 maio 2019 | publicado: 28 jun. 2019.

Apresentação anterior: não houve.

Licença CC BY-NC atribuição não comercial. Com essa licença é permitido acessar, baixar (download), copiar, imprimir, compartilhar, reutilizar e distribuir os artigos, desde que para uso não comercial e com a citação da fonte, conferindo os devidos créditos de autoria e menção à Reciis. Nesses casos, nenhuma permissão é necessária por parte dos autores ou dos editores. 


\section{Introdução}

De acordo com dados da Associação Nacional de Travestis e Transexuais (Antra)1, estima-se que, no Brasil, 90\% das mulheres transexuais e travestis estejam se prostituindo. Estes dados evidenciam a dificuldade de pessoas trans ocuparem um espaço formal e legítimo nas organizações - o que muitas vezes as destina para um único meio de sobrevivência, a prostituição.

A parcela que consegue se inserir no ambiente organizacional apresenta diversas dificuldades para manter-se nele, principalmente tendo em vista o modelo de gestão baseado em privilégios que busca controlar a diversidade ao invés de promover espaços de inclusão e participação. Entende-se na comunicação uma possibilidade de deslocar questões políticas e sociais para dentro dos espaços organizacionais e viabilizar o acesso e a inclusão de travestis nesses ambientes.

Diante disso questiona-se: qual o papel da comunicação na construção de espaços organizacionais inclusivos para a população travesti?

Assim, este artigo tem como principal objetivo provocar reflexões sobre o papel da comunicação na inclusão de travestis no ambiente organizacional, além de auxiliar a compreensão sobre gênero e a humanização da travesti, dialogar com as vivências relacionadas à educação e ao mercado de trabalho e criar um espaço de discussão a respeito da questão travesti diante das organizações.

Este estudo pode servir como base para novas reflexões acerca da comunicação como protagonista na busca pela inclusão da diversidade em suas ações por meio de uma visão comunicacional humana, social e política que viabilize a transformação social, bem como motivar novas pesquisas que tenham o intuito de gerar novos olhares comunicacionais para a população travesti e criar medidas para que ela tenha seus direitos garantidos e alcance voz e espaço nas organizações.

Por meio de um ensaio teórico, de caráter bibliográfico e interpretativo, busca-se construir um referencial conceitual sobre a relação entre gênero e comunicação, e como esta pode influenciar e criar espaço para a inclusão travesti no ambiente organizacional. Como forma de materializar o resultado interpretativo desta reflexão, propõe-se um esboço de diretrizes de comunicação para a criação de um ambiente preparado para receber a travesti.

Com base nisso, este ensaio inicia-se com a apresentação do conceito de gênero enquanto construção social, travestilidade e o contexto social vivenciado pelas travestis, que envolve discriminação e exclusão de suas vivências diante de uma sociedade estruturada na transfobia. Após essa discussão, busca-se dialogar com o mercado de trabalho e entender esse ambiente como excludente e privativo ao acesso de identidades travestis, o que abre espaço para se pensar políticas que garantam a inclusão nas organizações - o que se concretiza, conforme é proposto como reflexão principal neste ensaio, pela ação comunicacional nas organizações a partir do momento em que se observa seu potencial transformador e humano diante da subjetividade travesti.

\section{Gênero e travestilidade}

Parte-se da reflexão sobre gênero como uma construção social, caracterizada por variáveis culturais que modificam como a leitura dos indivíduos e de seus significados é realizada, além de como ocorre a associação ao que seria a definição de masculinidade e feminilidade. Assim, as múltiplas formas de experienciar gênero não estariam definidas pelo órgão genital, e ele não seria o determinador absoluto de nossas vivências, percepções, sentimentos e desejos.

A construção de gênero se dá de maneira política, visto que há uma hierarquia na relação masculinofeminino expressa em modelos desiguais de direitos e participação cívica. Essa estrutura institui uma série de características do que se categoriza ser feminino ou masculino por meio de processos existentes ao longo do tempo. Dessa forma, o corpo, por traços pré-definidos socialmente, é que recebe o gênero e não aquilo que 
o determina. "Gênero é o aparato pelo qual a produção e a normalização do masculino e do feminino se manifestam junto com as formas intersticiais, hormonais, cromossômicas, físicas e performativas que o gênero assume. Supor que gênero sempre e exclusivamente significa as matrizes 'masculino' e 'feminina' é perder de vista o ponto crítico de que essa produção coerente e binária é contingente, que ela teve um custo, e que as permutações de gênero que não se encaixam nesse binarismo são tanto parte do gênero quanto seu exemplo mais normativo. Assimilar a definição de gênero à sua expressão normativa é reconsolidar inadvertidamente o poder da norma em delimitar a definição de gênero. Gênero é o mecanismo pelo qual as noções de masculino e feminino são produzidas e naturalizadas, mas gênero pode muito bem ser o aparato através do qual esses termos podem ser desconstruídos e desnaturalizados”2.

Em uma sociedade determinada pelo binarismo em suas mais diversas instâncias, a divisão entre o feminino e o masculino, macho e fêmea, age de forma a reprimir outras identidades que não sejam as sustentadas pelas normas heterossexuais. "A matriz cultural por intermédio da qual a identidade de gênero se torna inteligível exige que certos tipos de 'identidade' não possam 'existir' - isto é, aquelas em que o gênero não decorre do sexo e aquelas em que as práticas do desejo não ‘decorrem’ nem do ‘sexo’ nem do ‘gênero'. Nesse contexto, ‘decorrer’ seria uma relação política de direito instituído pelas leis culturais que estabelecem e regulam a forma e o significado da sexualidade. Ora, do ponto de vista desse campo, certos tipos de 'identidade de gênero’ parecem ser meras falhas do desenvolvimento ou impossibilidades lógicas, precisamente porque não se conformaram às normas da inteligibilidade cultural"3.

O afastamento desse padrão simboliza um desvio que coloca o sujeito como algo estranho, esquisito, excêntrico ${ }^{4}$. Os indivíduos 'desviantes' colocam em xeque essa percepção de que o gênero é ligado ao sexo biológico, o que leva o sistema a considerar a transexualidade anormal e patológica. Ou seja, não atender à norma estabelecida gera exclusões que também são políticas, porque definem quem 'pode' e quem 'não pode'. Um desses indivíduos 'desviantes' são as travestis.

Transexualidade, transgênero, travestilidade são formas identitárias de se expressar gêneros que confrontam a norma social manifestada na dualidade homem-mulher, na heterossexualidade e nos papéis de gênero. Essa normatividade decreta o que se considera verdade, aquilo que seria real, definindo corpos que podem existir ${ }^{5}$

O ser travesti pode ser definido como seres que são biologicamente definidos como masculinos, porém possuem identidade de gênero feminina e buscam representar essa identidade por meio de transformações corporais $^{6}$, materializando em seus corpos o gênero com o qual se identificam.

A pluralidade de experiências enquanto ser 'travesti' é abordada na literatura diante do 'sentir-se mulher', expressa como "uma interioridade que precisa ser externalizada na materialidade do corpo, compondo uma totalidade, que faz do corpo sexualizado o locus da produção de uma identidade que, mesmo fluida, se alicerça num sistema simbólico no qual as representações de gênero, sexualidade e corporalidade são categorias estruturantes e mutuamente referentes. Um gênero que pode ser transformado a fim de adequar o desejo - e, assim, a sexualidade - a valores morais que fixam papéis e prescrevem comportamentos cabíveis ao feminino"7.

Ainda que em alguns momentos reforcem a ordem binária, Larissa Pelúcio salienta que as travestis evidenciam que o gênero pode ser construído e isso as impede de serem reconhecidas como sujeitos dentro da norma e as coloca em lugares marginais, que são envoltos em repúdio, preconceito e exclusão ${ }^{7}$. Ser compreendido de forma marginalizada afeta a socialização, visto que a sociedade se estabelece por meio de um sistema classificatório que hierarquiza os indivíduos por meio de suas diferenças, auferindo um significado socialmente produzido a seres, objetos e comportamentos através da classificação concedida a eles ${ }^{8}$.

Ao pensar nessa hierarquização como uma pirâmide, o homem branco, cisgênero e heterossexual encontra-se no topo, enquanto as travestis e seus corpos abjetos são a base. As consequências da valorização da heteronorma e da exclusão e marginalização dos indivíduos que não fazem parte dela são percebidas pela transfobia, que pode ser definida como a aversão a pessoas transexuais e travestis. Ela ocorre diretamente 
através de discriminação, exclusão, ódio e violência física ou verbal. Mas também acontece de forma indireta com o reforço excessivo da matriz cultural normativa de gênero, por exemplo.

\section{Mercado de trabalho e vivência escolar}

A exclusão e a marginalização dos indivíduos fora da norma também se dão na instância do trabalho. Constituído socialmente a partir dos princípios da normatividade e do binarismo de gênero, o mercado de trabalho apresenta empecilhos para a inserção das travestis, e a falta de acesso acarreta grandes impactos na socialização desses indivíduos.

Parte-se do pressuposto de que o trabalho possui grande e fundamental influência no ser humano em nossa sociedade, visto que faz parte da inserção do indivíduo no contexto social e da sua construção pessoal, além de auxiliá-lo em seu sustento e satisfação de suas necessidades ${ }^{9}$. Deste modo, o trabalho é um dos grandes meios do ser humano sentir-se realizado e socializar, além de abrir caminhos para o aprendizado e para a criação. "A não oportunidade de se desenvolver profissionalmente é capaz de retirar do indivíduo a possibilidade de exercer funções que dariam a ele colocação e aceitação social, bem como pode gerar grande sofrimento psíquico e adoecimento"

A privação do acesso ao mercado costuma começar cedo para as travestis, já que a disciplina dos corpos, que regula gênero e sexualidade, também é reforçada no modelo de ensino dentro das escolas. Caracterizado por um processo de ensino que não aborda a multiplicidade de conceitos ligados ao gênero e à sexualidade, o sistema escolar acaba por excluir esses indivíduos de sua narrativa e tenta enquadrá-los dentro da norma social binária baseada em seus genitais.

Como a inserção no mercado está diretamente relacionada com o estudo e a qualificação dos indivíduos, as pessoas LGBTQIA+ (Lésbicas, Gays, Bissexuais, Transexuais, Queer, Intersexo, Assexuais e mais), em especial travestis e transexuais, se deparam com obstáculos, visto que encontram empecilhos na permanência escolar por conta dos preconceitos a que são submetidas desde a infância. Dessa forma, "podemos afirmar que juntamente com os preconceitos presentes nos mais diversos contextos, a baixa escolaridade pode ser considerada responsável pelas dificuldades das transexuais alcançarem melhores condições profissionais. Ao abandonarem os estudos, ficam impedidas de terem uma capacitação adequada para o mercado de trabalho, que cada vez exige mais qualificação e escolaridade" .

A escola mostra-se como fator fundamental para assegurar maior facilidade de acesso ao mercado, isso sem considerar outros fatores como raça, sexualidade e identidade de gênero. Porém, a educação não é estabelecida da mesma forma para todos, principalmente quando se trata de indivíduos que se encontram às margens da norma, como é o caso da população trans, já que, de acordo com a pesquisa realizada por João Paulo Carvalho Dias, estima-se que o Brasil tenha $82 \%$ de evasão escolar de travestis e transexuais ${ }^{10}$.

A conservação da imagem normativa é vista como uma das características para a obtenção de qualificação, emprego e exercício da profissão. Diante disso, a imagem das travestis não é legitimada nesses espaços por conter traços ambíguos, em que não ocorre clareza do gênero associado à sua genitália, mas sim expressão associada a outro. "Basta uma rápida olhada nos anúncios de emprego para deixar claro que o mercado de trabalho possui uma estrutura segmentada pelo gênero - definido pela dicotomia convencional homem/mulher. Muitos valores subjetivos e avaliações estão embutidos nesta divisão sobre aquilo que um homem ou uma mulher pode ou deve fazer. Pessoas com uma ambiguidade de gênero poderiam causar confusão e sentir rejeição, por não se encaixarem facilmente nos nichos que existem no mercado de trabalho. A mesma ambiguidade pode ser vista como algo capaz de perturbar o desempenho da função, principalmente num mundo onde muitas ocupações se exercem vinculadas à apresentação e conservação da imagem"11. 
“As normas de gênero só conferem inteligibilidade, ou seja, vida, àqueles seres que estão alocados em gêneros apropriados aos corpos sexuados" 5 . Dessa forma, muitos desses indivíduos, que 'fogem à norma', são privados de acesso, o que no mercado pode ser observado logo no início dos processos de recrutamento e seleção.

Em 2015, um estudo da companhia Elancers, atuante em recrutamento e seleção, revelou que 20\% das organizações brasileiras não contratariam funcionários que fossem LGBTs assumidos e 7\% afirmaram não contratar sob hipótese alguma candidatos LGBTs, enquanto 11\% das empresas só considerariam a contratação se não houvesse possibilidade de alcançar um cargo de maior visibilidade ou chefia ${ }^{10}$.

A opressão e a transfobia se iniciam, nesses processos, pelo não reconhecimento da identidade travesti, manifestado pela não utilização do nome sociali e uso de pronomes masculinos como tentativa de reforçar a normatividade ao se deparar com documentos com sexo e nome de registro e a diferença na imagem e aparência. Nesse momento, muitas são barradas por não possuírem o perfil adequado para a seleção.

Por meio de estudos e pesquisas, é possível perceber a dificuldade das travestis ingressarem num mercado em que muitas já se deparam com um grande problema nas etapas de seleção, visto que os entrevistadores demonstram espanto e desconforto ao entrevistá-las ou mudam suas visões sobre as entrevistadas ao descobrirem que são pessoas transgêneras ${ }^{9,12-16}$.

Nos poucos casos em que uma travesti consegue ser efetivada, ela ainda tem grandes chance de ser alvo de discriminação por parte de seus colegas de trabalho e seus superiores. Mesmo contratada, depara-se com dificuldades para o uso do nome social, recebendo muitas vezes um tratamento no masculino e uso do nome de registro em crachás e outras formas de identificação - além de outros empecilhos, como a obrigatoriedade de usar o banheiro masculino, por exemplo, o que causa humilhação e desconforto ${ }^{12,13,17-19}$.

Logo, pode-se perceber que o espaço para as travestis no mercado de trabalho quase não existe, o que torna profundamente necessária a concepção de programas e iniciativas de valorização profissional, acesso à qualificação e oportunidades de trabalho que ajudem na propagação de ações que promovem o combate à discriminação. Valorizar a diversidade e combater o preconceito são argumentos defendidos amplamente pelo senso comum; porém, é difícil que isso ocorra de formas efetivas dentro de organizações.

Essa valorização poderia ser garantida mediante uma gestão que crie espaço para a inclusão da diversidade em todas as suas instâncias e manifeste-se "na promoção de interações, encontros, compartilhamentos de perspectivas, expectativas e aprendizados em ambiente de alta cooperação e desempenho. Ambientes respeitosos e inclusivos permitem essa interação criativa, que gera inovação e construção de soluções interessantes para a diversidade de demandas com as quais a empresa deve se relacionar"20.

Para criar uma real inclusão e participação da diversidade nas organizações, é preciso deslocar questões políticas e sociais para dentro dos espaços organizacionais - o que significa ir além dos discursos e criar medidas para que os direitos humanos e o acesso ao mercado sejam garantidos para todas. Além de espaço, também é preciso dar visibilidade e voz para que as travestis possam ser parte integrante do mercado de trabalho e protagonizar o diálogo sobre o tema. Isso pode ser garantido através de políticas e práticas que vão ao encontro do papel social, político e constitutivo da comunicação para a construção de espaços organizacionais inclusivos.

\section{Comunicação e inclusão de travestis nos espaços organizacionais}

É costumeiro narrar a diversidade simplificando-a, criando uma imagem do outro sem considerar suas complexidades. Comunica-se com o outro de acordo com o estereótipo, com a construção de sua imagem sem permitir que ele questione ou interfira nessa representação.

i Em janeiro de 2018, foi homologada pelo Ministério da Educação a resolução que autoriza o uso do nome social de travestis e transexuais nos registros escolares. Dessa forma, os estudantes maiores de 18 anos podem solicitar sua matrícula utilizando o nome social; no caso de estudantes com menos de 18 anos, a solicitação deve ser realizada por seus representantes legais. 
Quando focada somente na representação dos padrões, a comunicação exclui os corpos não binários e fora da norma. Cria-se uma barreira entre o 'nós', dentro da norma, e o 'eles', indivíduos fora da norma, o que impede a existência de uma comunicação recíproca que represente todos os indivíduos e suas necessidades e exercite os direitos humanos. Em especial, quando relacionada às organizações e questões ligadas à inserção da população travesti em um ambiente de trabalho em que se exercite os direitos humanos, a comunicação possui grande potencial transformador para a garantia de espaços que sejam, de fato, inclusivos.

Há autores que explicam ${ }^{21}$ - por meio de conceitos, da teoria estrutural de Blau ${ }^{\text {ii }}$ e da teoria dos estados de expectativa de Berger e Zelditchiii - que as identidades de gênero e raça são as que mais causam impacto nas interações sociais, principalmente no acesso a recursos, o que as tornam indicadores independentes de status que determinam a inclusão ou a exclusão dos sistemas sociais.

Não ter representantes dessa identidade de gênero nas organizações ajuda a estigmatizar o papel da travesti diante do mercado, tanto para a sociedade em geral quanto para as próprias travestis que, ao não ver outras ocupando o espaço organizacional, constroem uma percepção de mundo em que elas não possuem direito a esses espaços.

Essas representações regulam como os sujeitos interagem com os outros, com o mundo e, nesse caso, com as organizações. Quando se pensa em um espaço de igualdade e inclusão, é necessária a representação e interação ativa de todos os indivíduos. Assim, é "fundamental a construção de políticas de inclusão para o reconhecimento da diferença para desencadear uma revolução conceitual que conceba uma sociedade onde todos devem participar com direito de igualdade e de acordo com suas especificidades”22.

Para que seja possível pensar a diversidade e inclusão dentro das organizações, faz-se necessário humanizar a forma como se pensa os espaços organizacionais. Dessa maneira, tira-se o foco da visão habitual de gestão centrada no desempenho e na produtividade, que deixa de considerar as subjetividades dentro das organizações, e vê-se necessária a humanização. "A humanização é mais integralmente percebida quando a diferença é reconhecida e tematizada na vida organizacional. $\mathrm{E}$ ao falar em diferença, aqui me refiro a formas de subjetividade humana como as articuladas por meio de raça, classe, gênero, sexualidade, saúde etc. e às formas de pensar e construir vocabulários e conhecimento para compreender a vida organizacional”²3.

Essa dimensão humana, muitas vezes esquecida, pode ser exercida através da comunicação, porque "as organizações são formadas por pessoas que se comunicam entre si e que, por meio de processos interativos, viabilizam o sistema funcional para a sobrevivência e consecução dos objetivos organizacionais em um contexto de diversidade, conflitos e transações complexas”²3.

Nessa relação com o outro através da comunicação, os indivíduos são afetados e afetam o ambiente organizacional por meio de suas narrativas, que são ligadas às identidades de cada indivíduo e à maneira como se relacionam com a sociedade - o que forma sua visão de mundo e como ela é expressa para o outro. Porém, o que ocorre é que o tecido social define os espaços de quem narra e quem é narrado, ou seja, "os regimes narrativos instituídos permitem, ou demandam, que apenas uma pequena parcela do mundo vivido possa ser convertido em uma narrativa, e menos espaço ainda existe para que essas narrativas se tornem conhecidas em um espaço público”24. Isso acaba por reduzir algumas narrativas ao senso comum, minimizando sua complexidade e construindo estereótipos.

Esse fenômeno de estereotipação acontece com frequência em relação à vivência travesti. Suas narrativas são direcionadas ao lugar comum, apagando suas subjetividades e as colocando sob uma visão discriminatória que as percebe como seres anormais, as excluem dos espaços organizacionais e as direcionam somente para a margem. A inclusão da diversidade nas organizações perpassa pela mudança do foco narrativo da

ii Blau, 1977 apud $^{21}$

iii Berger, Zelditch, 1985 apud $^{21}$ 
normatividade para uma construção, por meio da humanização da comunicação como função social e política, em que as travestis possam conquistar espaços de fala e protagonismo de suas narrativas.

Porém, questiona-se se essa mudança realmente acontece na prática de gestão da diversidade ou se as ações, em teoria, não discriminatórias só existem pela busca de legitimidade social. Isto posto, é "de se considerar a efetividade e os desdobramentos dos discursos empresariais pró-diversidade. A efetividade se refere à intensidade com que são praticadas as políticas de igualdade de oportunidades entre indivíduos de segmentos socialmente discriminados. Os desdobramentos são um efeito da adoção ou não de tais medidas, pois a legitimidade é ameaçada quando os indivíduos não acreditam nas políticas pela ausência de oportunidades de ascensão e de reconhecimento" 25 .

Essa efetividade pode ser garantida através de práticas de comunicação que "ampliam os lugares e processos de escuta procurando compreender a diversidade de ideias e posturas dos públicos, interpretar tal diversidade e, em diálogo, (re)construir a rede simbólica da entidade”26. Dessa forma, o papel da comunicação faz-se necessário para compor um diálogo recíproco, entre as organizações e a sociedade, que viabilize o exercício dos direitos humanos e a construção de uma sociedade igualitária, justa e livre, agindo como potencializadora das oportunidades de mudança e de transformação social ${ }^{27}$.

Deve-se promover e gerir a diversidade de modo que o diálogo sobre gênero seja constantemente estimulado. Essa gestão precisa considerar as singularidades e respeitar os direitos humanos com o propósito de incentivar a pluralidade e o aprendizado com os diferentes públicos. Fazer isso, "significa, portanto, dar voz, visibilidade e estimular a expressão da diversidade humana para que todos possam interagir a partir de suas realidades para gerar novos aprendizados e soluções que as pessoas sozinhas ou em ambientes muito homogeneizantes não conseguem gerar”22.

Ainda que a prática de inclusão da diversidade esteja relacionada com o trabalho desenvolvido pelas áreas da comunicação, isto nem sempre está inserido nos programas e planejamentos de comunicação das organizações. Ou, quando inserida, possui um viés ligado ao politicamente correto e à construção de uma imagem organizacional positiva sem que ocorra uma real mudança com base no desenvolvimento social, nos direitos humanos e na cidadania. Muitas vezes, "em vez de usar as práticas comunicacionais para empoderar os cidadãos para trabalharem em grupos e construírem condições sociais justas, as relações públicas fazem o oposto, encorajando uma atitude passiva" ${ }^{28}$.

A comunicação permite a construção de um modelo de transformação social com base em um desenvolvimento sustentável e participativo com foco no exercício da cidadania ${ }^{29}$, que é fundamentada nos princípios básicos da "liberdade e [d]a igualdade, e o desenvolvimento de uma sociedade pode ser medido pelo grau com que estes princípios são expressos e exercitados na forma de direitos e deveres”²9. Cicília Peruzzo ainda recorda que, na atual estrutura social marcada pela desigualdade, "uns são mais cidadãos que outros, sendo estes a maioria"29.

Exercer a cidadania e a inclusão significa respeitar e garantir direitos e participação de todas as identidades de gênero. E não adianta só a inserção; é preciso que o comunicador desenvolva políticas nos espaços organizacionais e crie diálogo com essas identidades, afinal "estar dentro de determinados espaços sociais não é inclusão, visto que, a exclusão está infiltrada nas relações"22. Faz-se necessária a criação de ações afirmativas, ou seja, políticas que visem garantir o acesso das travestis ou de outros grupos que têm o acesso negado, mas é preciso ir além e possibilitar a permanência, que pode ser alcançada pela gestão da diversidade que não seja focada no controle dessas identidades ${ }^{30}$. Assim, o comunicador "trabalha para fazer possível uma comunicação que diminua o espaço das exclusões ao aumentar mais o número de emissores e criadores do que o dos meros consumidores. Essa reconfiguração do comunicador como mediador volta-se basicamente para 
o entendimento da comunicação como a colocação em comum de sentidos da vida e da sociedade. O que implica dar prioridade ao trabalho de ativação, nas pessoas e nos grupos, de sua capacidade de narrar/construir sua identidade, pois a relação da narração com a identidade não é meramente expressiva, mas constitutiva: a identidade individual ou coletiva não é algo dado, mas em permanente construção, e se constrói narrando-se, tornando-se relato capaz de interpelar os demais e deixar-se interpelar pelos relatos dos outros"28.

Para tanto, as organizações necessitam de um profissional de comunicação "como ativista organizacional, que exerce a consciência na organização, resistindo às estruturas de poder dominantes, principalmente quando essas estruturas não são inclusivas”28. Um perfil de agente de mudança focado na transformação e humanização dos espaços organizacionais atuando no processo decisório para a emancipação e protagonismo dos atores sociais e da diversidade.

Diante dessa perspectiva, definem-se algumas diretrizes que complementam a reflexão apresentada neste trabalho. Elas têm o objetivo de auxiliar a redução da transfobia e dos estigmas relacionados às travestis e inserir o debate sobre o tema no ambiente organizacional.

\section{Diretrizes comunicacionais para a criação de um ambiente preparado para receber a travesti}

A proposição de diretrizes de comunicação para a construção de espaços organizacionais inclusivos para as travestis resulta do estudo de suas realidades e da reflexão acerca do potencial transformador da comunicação nas organizações.

As diretrizes foram elaboradas com o intuito de apontar alguns aspectos necessários para que a comunicação seja ativa na promoção da inclusão de travestis nas organizações e exerça um posicionamento efetivo que colabore para a criação e manutenção de ambientes organizacionais que não excluam suas narrativas.

Elas têm por objetivo contribuir para a diminuição da transfobia e dos estigmas relacionados às travestis e colaborar para a discussão do tema e melhor entendimento sobre a questão dentro do ambiente organizacional. Apresentam-se alguns focos que intencionam uma mudança no viés excludente e a humanização do olhar sobre o outro, pretendendo criar uma base para que as travestis façam parte dos espaços organizacionais. 
Quadro 1-Esboço de diretrizes comunicacionais para criação de um ambiente preparado para receber a travesti

Diretrizes comunicacionais para a criação de um ambiente preparado para receber a travesti

\begin{tabular}{|c|c|}
\hline I & $\begin{array}{l}\text { Promoção do diálogo e compromisso com o respeito: toda e qualquer ação comunicacional deve ser } \\
\text { pautada pelo diálogo e pela humanização. Precisa sempre priorizar o respeito a todas as identidades de } \\
\text { gênero, através de mecanismos que promovam a inclusão e o desenvolvimento sustentável, além de } \\
\text { criar conexões com as narrativas travestis. O planejamento de comunicação deve utilizar-se de canais } \\
\text { que prezem o diálogo e a troca entre os indivíduos, de forma simétrica e com mão dupla entre todos na } \\
\text { organização. }\end{array}$ \\
\hline II & $\begin{array}{l}\text { Incentivo ao uso de ações afirmativas e políticas de permanência: para ampliar a participação travesti } \\
\text { no mercado, o relações-públicas precisa estimular sua inclusão por meio de ações afirmativas e políticas } \\
\text { de permanência. Para pensar em um espaço igualitário e inclusivo, faz-se necessária a participação ativa } \\
\text { de todos de acordo com suas subjetividades. A criação de ações afirmativas, ou seja, políticas que visam } \\
\text { garantir o acesso de grupos marginalizados é um dos primeiros passos para assegurar a inserção travesti } \\
\text { nas organizações e, por isso, deve ser incentivada. Mas é preciso ir além e possibilitar a permanência, } \\
\text { através de uma comunicação que busque diminuir o espaço das exclusões. }\end{array}$ \\
\hline III & $\begin{array}{l}\text { Adoção e fortalecimento de políticas de não discriminação e tratamento justo: definir políticas e práticas } \\
\text { de não discriminação desde o momento de recrutamento e seleção até o dia a dia organizacional, } \\
\text { estabelecendo medidas específicas para todo o processo comunicacional, seja ele interno ou externo. }\end{array}$ \\
\hline IV & $\begin{array}{l}\text { Fomento de espaços de discussão: um dos principais focos das relações públicas no ambiente } \\
\text { organizacional é fomentar espaços de discussão. O tema deve ser abordado em falas, eventos, } \\
\text { campanhas internas e documentos organizacionais, sempre buscando promover a inclusão e o respeito } \\
\text { às travestis. }\end{array}$ \\
\hline V & $\begin{array}{l}\text { Garantia de tratamento justo e com respeito para todas as travestis, respeitando seus nomes e o } \\
\text { pronome feminino em toda a comunicação da organização. Implementar um canal em que as travestis } \\
\text { possam reclamar casos de violência e discriminação, com profissionais capacitados para atendê-las e } \\
\text { com a aplicação das medidas de responsabilização necessárias para que estes casos não ocorram. }\end{array}$ \\
\hline VI & $\begin{array}{l}\text { Desenvolvimento de programas de capacitação para a gestão: para que a inclusão ocorra, é necessário } \\
\text { que os gestores sejam capacitados sobre o tema da identidade de gênero e sobre sua responsabilidade } \\
\text { para garantir um ambiente inclusivo, diverso e igualitário. Criar programas internos de capacitação e } \\
\text { incentivo a práticas de gestão, pautadas nos direitos humanos, que viabilizem a discussão, o respeito e a } \\
\text { visibilidade do tema nas organizações. }\end{array}$ \\
\hline VII & $\begin{array}{l}\text { Inserção das narrativas travestis na comunicação organizacional: fazer uso da comunicação e das } \\
\text { relações públicas para dar protagonismo às vivências trans e travestis, alinhamento do discurso } \\
\text { organizacional com as identidades trans. Elaborar e incentivar a valorização dessas identidades em } \\
\text { campanhas internas e externas, além de abordar questões políticas como a violência e a falta de acesso. } \\
\text { Inserir a temática no calendário organizacional, bem como nos tópicos de ações sociais, com o objetivo } \\
\text { de educar para a equidade e empoderar as travestis. }\end{array}$ \\
\hline VIII & $\begin{array}{l}\text { Criação de medidas para o acompanhamento da comunicação: atentar-se para toda a comunicação } \\
\text { organizacional, buscando não produzir nenhum tipo de conteúdo que contenha preconceito com as } \\
\text { travestis ou que reforce o padrão normativo de gênero. }\end{array}$ \\
\hline IX & $\begin{array}{l}\text { Criação de mecanismos de capacitação das travestis: desenvolver ou apoiar programas educacionais e } \\
\text { de capacitação profissional garantindo melhores oportunidades de trabalho e qualidade de vida para as } \\
\text { travestis. }\end{array}$ \\
\hline$X$ & $\begin{array}{l}\text { Incentivo a projetos de educação permanente: tendo em vista a realidade travesti, que muitas vezes } \\
\text { apresenta problemas e defasagens em relação à vida escolar, estimular e desenvolver projetos de } \\
\text { educação continuada e instrutiva permitindo que este público alcance oportunidades de aprendizagem e } \\
\text { desenvolvam suas habilidades. }\end{array}$ \\
\hline
\end{tabular}

Fonte: Os autores (2019). 


\section{Considerações finais}

Quando o foco do olhar é direcionado para outras identidades de gênero, como as travestis, encontrase uma realidade de exclusão e marginalização em diversas instâncias sociais. Através do levantamento feito durante o estudo, com base em pesquisas ${ }^{2,3,5,7}$, entende-se gênero como construção dentro de uma estrutura social de relações de poder que hierarquiza e normatiza as vivências de gênero. De acordo com a estrutura social definem-se papéis de gênero para o que se considera feminino ou masculino e eles são impostos aos indivíduos com base em suas genitálias. Isso molda a forma como se vive e se constroem os corpos; porém, nem todos se enquadram nesse padrão. Ao não se perceber como parte dessa norma, as travestis desconstroem padrões e constroem suas identidades fora do que é esperado pelo sistema. Essa construção é expressa por suas falas, seus desejos e seus corpos e, ao se depararem com a hierarquia social, encontram dificuldades e barreiras que impedem seus acessos aos espaços sociais desde muito cedo. Essas dificuldades se iniciam no contexto familiar, acentuam-se no ambiente escolar e percorrem toda a busca de inserção no mercado de trabalho. O espaço organizacional ainda se apresenta muito hostil para a inserção travesti, e é preciso criar políticas que garantam não só essa inserção, como a permanência dessas pessoas nas organizações.

Considerando esses aspectos, percebe-se a necessidade de provocar uma reflexão sobre o papel da comunicação enquanto área de conhecimento e profissão diante desse assunto. Principalmente porque deve-se considerar o quanto a comunicação contribui para a exclusão travesti, seja ao reforçar a norma, ao intensificar a ausência de representatividade, seja ao excluir suas narrativas dos contextos comunicacionais ou ao reiterar estereótipos. Por outro lado, quando se escreve sobre a comunicação para a transformação social e para o exercício da cidadania, evidencia-se a importância de um profissional consciente, que atue de forma política e social e que rompa os paradigmas ao contribuir para que as travestis alcancem seu espaço dentro das organizações, questionando a forma normativa de se comunicar que contribui para a exclusão social ${ }^{30}$.

Faz-se necessário um olhar crítico sobre a forma que se pensa a comunicação e a gestão quando voltadas para a diversidade. Estamos marginalizando as travestis ou as tornando protagonistas de suas narrativas? $\mathrm{O}$ que estamos fazendo para contribuir para a manutenção da norma, do preconceito e da transfobia? Até que ponto estamos auxiliando e criando espaços para a diversidade? Ou será que estamos criando formas de gerir e controlar a diversidade sem que haja diálogo sobre suas subjetividades? Estão sendo criados mecanismos de inserção dessa diversidade no espaço organizacional? Além disso, estão sendo criadas políticas que garantam a permanência da diversidade nesses espaços? Essas questões foram suscitadas ao longo desta pesquisa e poderão nortear outras iniciativas de se investigar a comunicação e o contexto organizacional com vistas à inclusão, não só das travestis, mas, sobretudo, das minorias. Não por acaso essas são algumas perguntas que comunicadores sociais e profissionais de comunicação precisam começar a fazer e refletir, de forma crítica, sobre os caminhos que estão fazendo com a comunicação para a transformação social. Acredita-se que a comunicação, com foco no ativismo social, é capaz de exercer um posicionamento muito mais efetivo para combater os preconceitos nas organizações e colaborar para a criação de um ambiente inclusivo e de diálogo no qual as travestis consigam exercer o protagonismo das narrativas organizacionais.

Por isso, foram pensados alguns caminhos para se iniciar esse processo, através da indicação de algumas diretrizes para a criação de um ambiente preparado para receber a travesti, para valorizá-la e reconhecê-la como indivíduo e também como parte de um todo.

Porém, para que isso aconteça é preciso mudar esse viés inconsciente que leva a excluir as travestis, e a diversidade como um todo, das narrativas e dos públicos considerados válidos para a organização. Faz-se necessário aprofundar os estudos, entender outras realidades, sair do lugar-comum e humanizar o olhar sobre o outro para que, dessa forma, a comunicação possa exercer seu real potencial de transformação. 


\section{Referências}

1. Associação Nacional de Travestis e Transexuais (Antra). Mapa dos assassinatos de travestis e transexuais no Brasil em 2017 [Internet]. Brasil: Associação Nacional de Travestis e Transexuais (ANTRA); 2017 [citado 01 nov. 2018]. Disponível em: https://antrabrasil.files.wordpress.com/2018/02/relatc3b3riomapa-dos-assassinatos-2017-antra.pdf.

2. Butler J. Regulações de Gênero. Cad. Pagu [Internet]. 2016 jan./jun. [citado 01 nov. 2018];(42):249-74. Disponível em: http://www.scielo.br/pdf/cpa/n42/0104-8333-cpa-42-00249.pdf.

3. Butler J. Problemas de gênero: feminismo e subversão da identidade. Aguiar R, tradutor. Rio de Janeiro: Civilização Brasileira; 2003.

4. Louro GL. Currículo, gênero e sexualidade: o normal, o diferente e o excêntrico. In: Louro GL, Felipe J, Goellner SV. Corpo, gênero e sexualidade: um debate contemporâneo. Petropólis: Editora Vozes; 2012. p. 41-52.

5. Bento B. O que é transexualidade?. São Paulo: Brasiliense; 2008.

6. Silva, JM. A cidade dos corpos transgressores da heteronormatividade. In: Silva JM, organizadora. Geografias subversivas: discursos sobre espaço, gênero e sexualidades. Ponta Grossa: TODAPALAVRA; 2009. p. 135-149.

7. Veras EF. PELÚCIO, Larrisa. Abjeção e desejo: uma etnografia travesti sobre o modelo preventivo de aids. Ver. Est. Fem. 2012 maio;20(1):320-322. doi: http://dx.doi.org/10.1590/S0104-026X2012000100019.

8. Simões JA, França IL, Macedo M. Jeitos de corpo: cor/raça, gênero, sexualidade e sociabilidade juvenil no centro de São Paulo. Cad. Pagu [Internet]. 2010 jun./dez. [citado 01 nov. 2018];(35):37-78. Disponível em: http://www.scielo.br/pdf/cpa/n35/n35a3.pdf.

9. Souza HA. Os desafios do trabalho na vida cotidiana de mulheres transexuais. [dissertação]. Campinas: Pontifícia Universidade Católica de Campinas; 2012 [citado 01 nov. 2018]. 127 p. Disponível em: http:// www.bibliotecadigital.puc-campinas.edu.br/tde arquivos/6/TDE-2013-02-05T062126Z-1768/Publico/ Heloisa\%20Aparecida\%20de\%20Souza.pdf.

10. Cerioni C. Por que empresas que contratam LGBT são mais inovadoras. Rev. Exame [Internet]; 2016 set 30. [citado 01 nov. 2018]. Disponível em: https://exame.abril.com.br/negocios/por-que-empresas-quecontratam-lgbt-sao-mais-inovadoras/.

11. Adelman M, Ajmaime E, Lopes SL, Savrasoff T. Travestis e transexuais e os outros: identidade e experiências de vida. Gênero [Internet]. 2003 [citado 01 nov. 2018]; 4(1):65-100. Disponível em: http:// www.revistagenero.uff.br/index.php/revistagenero/article/view/238/158.

12. Anzolin B, Soares SM, Moreno AM. Travestis e transexuais: realidade na sociedade e no mercado de trabalho na cidade de Cascavel. Akrópolis - R. ciênc. hum. Unipar [internet]. 2013 jan./jun. [citado 01 nov. 2018]; 21(1):3-10. Disponível em: http://revistas.unipar.br/index.php/akropolis/article/view/5209/3013.

13. Cândido LB. Medo e preconceito: experiências de transgêneros no contexto organizacional. In: Anais do IV Congresso Brasileiro de Estudos Organizacionais [Anais do congresso na Internet]; 2016 out. 19-21 [citado 01 nov. 2018]. Porto Alegre, RS; 2016. Disponível em: https://anaiscbeo.emnuvens.com.br/cbeo/ article/view/61/53.

14. Moura RG, Lopes PL. Comportamento organizacional frente à diversidade: a inclusão de travestis e transexuais no mercado de trabalho. In: XIV Simpósio de Excelência em Gestão e Tecnologia; 2017 out. 26-27; Resende, RJ. 2017 [citado 01 nov. 2018]. Disponível em: https://www.aedb.br/seget/arquivos/ artigos17/1182593.pdf.

15. Moura RG, Lopes PL. O preconceito e a discriminação de transgêneros no processo de recrutamento e seleção de pessoal: uma revisão bibliográfica. In: XI Simpósio de Excelência em Gestão e Tecnologia; 2014 out. 22-24; Resende, Rio de Janeiro. [citado 01 nov. 2018]. Disponível em: https://www.aedb.br/ seget/arquivos/artigos14/36520376.pdf.

16. Braz EC. As travestis e suas experiências no mercado de trabalho formal e informal em Campina GrandePB (2000-2010) [Monografia]. Campina Grande: Universidade Estadual da Paraíba; 2012 [citado 01 nov. 2018]. 46 p. Disponível em: http://dspace.bc.uepb.edu.br/jspui/bitstream/123456789/3081/1/PDF\%20 -\%20Ednaldo\%20da\%20Costa\%20Braz.pdf.

17. Rondas LO, Machado LRS. Inserção profissional de travestis no mundo do trabalho: das estratégias pessoais às políticas de inclusão. Rev. Pesqui. Prát. Psicossociais [Internet]. 2015 jan./jun. [citado 01 nov. 2018];10(1):192-205. Disponível em: http://pepsic.bvsalud.org/pdf/ppp/v10n1/16.pdf. 
18. Kaffer KK, Ramos FG, Alves AL, Tonon L. A transexualidade e o mercado formal de trabalho: principais dificuldades para a inserção profissional. Anais do IV Congresso Brasileiro de Estudos Organizacionais; 2016 out. 19-21 [citado 01 nov. 2018]. Porto Alegre, Rio Grande do Sul. Disponível em: https:// anaiscbeo.emnuvens.com.br/cbeo/article/view/52/44.

19. Licciardi N, Waitmann G, Oliveira MHM. A discriminação de mulheres travestis e transexuais no mercado de trabalho. Rev. Cient. Hermes [Internet]. 2015 nov. [citado 01 nov. 2018]; 14:201-2018. Disponível em: http://www.fipen.edu.br/hermes1/index.php/hermes1/article/view/210/pdf.

20. Ethos. O compromisso das empresas com os direitos humanos LGBT [Internet]. São Paulo: Instituto Ethos; 2013 [citado 01 nov. 2018]. Disponível em: https://www.ethos.org.br/wp-content/ uploads/2013/12/Manual-LGBT Dez 2013.pdf.

21. Nkomo SM, Cox JT. Diversidade e identidade nas organizações. In: Clegg SR, Hardy C, Nord WR, organizadores. Handbook de estudos organizacionais. São Paulo: Atlas; 2014. p. 332-358.

22. Almeida D. Inclusão social: os desafios da cultura organizacional inclusiva para o profissional de relações públicas. Anais da Conferência Brasileira de Folkcomunicação-Folkcom [Anais do congresso na Internet]; 18 abr. 2017; Recife, Pernambuco. Recife: Folkcom, 2017 [citado 01 nov 2018]. Disponível em: http:// anaisfolkcom.redefolkcom.org/index.php/folkcom/article/view/55.

23. Kunsch MMK. A dimensão humana da comunicação organizacional. In: Kunsch MMK. A Comunicação como fator de humanização nas organizações. São Caetano do Sul: Difusão Editora; 2010. p. 41-60.

24. Martino LMS. De um eu ao outro: narrativa, identidade e comunicação com a alteridade. Parágrafo [Internet]. 2016 jan./jun. [citado 01 nov. 2018];4(1):40-49. Disponível em: http://revistaseletronicas. fiamfaam.br/index.php/recicofi/article/view/377/376.

25. Saraiva LAS, Irigaray HAR. Políticas de diversidade nas organizações: uma questão de discurso?. Rev. adm. empres. [Internet]. 2009 set. [citado 01 nov. 2018];49(3):337-348. Disponível em: http://www. scielo.br/scielo.php?script=sci arttext\&pid=S0034-75902009000300008\&lng=en\&nrm=iso.

26. Figueira J. Olhares cruzados sobre comunicação organizacional e relações públicas à luz do paradigma da complexidade. In: Ruão T, Freias R, Ribeiro P, Salgado, P, organizadores. Comunicação organizacional e relações públicas: horizontes e perspectivas. Relatório de um debate Centro de Estudos de Comunicação e Sociedade; 2014; Braga, Portugal. Portugal: Universidade do Minho; 2014. p. 58-63.

27. Murade JFG. Relações públicas na construção da cidadania dos grupos populares. In: Kunsch MMK, Kunsch WL, organizadores. Relações públicas comunitárias. São Paulo: Summus; 2007. p. 150-164.

28. Salvatori PCG. Relações públicas, ativismo e cidadania: relação dialógica para transformação da sociedade. In: Scroferneker CMA, Amorim LR, organizadoras. (Re) leituras contemporâneas sobre comunicação organizacional e relações públicas. Porto Alegre: EDIPUCRS; 2017. p. 193-205.

29. Peruzzo CMK. Cidadania, comunicação e desenvolvimento social. In: Kunsch MMK, Kunsch WL, organizadores. Relações públicas comunitárias: a comunicação na perspectiva dialógica e transformadora. São Paulo: Summus; 2007. p. 45-58.

30. Alves MA, Galeao-Silva LG. A crítica da gestão da diversidade nas organizações. R. adm. empr. [internet]. 2004 jul./set. [citado 01 nov. 2018];44(3):1-10. Disponível em: http://www.scielo.br/pdf/rae/ v44n3/v44n3a03.pdf. 